\title{
COMPARISON OF SENTINEL-2 AND MULTITEMPORAL SENTINEL-1 SAR IMAGERY FOR MAPPING AQUACULTURE POND DISTRIBUTION IN THE COASTAL REGION OF BREBES REGENCY, CENTRAL JAVA, INDONESIA
}

\author{
Nurul Afdal HARIS ${ }^{1}$ (D), Sandiaga Swahyu KUSUMA ${ }^{1}$, Sanjiwana ARJASAKUSUMA ${ }^{1 *}$ (D), \\ Pramaditya WICAKSONO ${ }^{1}$ (D)
}

DOI: 10.21163/GT_2021.163.10

\begin{abstract}
:
The identification of land cover and land use is necessary to support the strategic management of coastal areas. The utilization of remote sensing technology such as synthetic aperture radar (SAR) data has been widely used for mapping the distribution of land cover and land use. This application includes the detection of aquaculture ponds in coastal areas due to SAR's sensitivity to surface water content. In addition, multitemporal Sentinel-1 data helps to distinguish between ponds and rice fields that possess a visually similar appearance during the flooding stage. This study aims to explore the accuracy of the gray level of co-occurrence model (GCLM) textures of multitemporal Sentinel-1 data for aquaculture pond mapping in Brebes Regency, Central Java Province, Indonesia. In addition, singledate Sentinel-2 optical imagery was used to compare the results from Sentinel-1 data. The Sentinel-2 data has been identified using supervised classifications, e.g., maximum likelihood (ML), minimum distance (MD), random forest (RF), and K-nearest neighbor (KNN) algorithms, and the most accurate algorithm was selected to classify the Sentinel-1 data using GLCM textures. The results indicated that the Sentinel-1 imagery showed the best results using GLCM metrics from VH polarization with an accuracy value of $92.2 \%$ using the ML algorithm, while the best results from Sentinel-2 were also produced using ML, with an $88.4 \%$ overall accuracy. These results demonstrate that multitemporal Sentinel-1 data have higher accuracy than Sentinel-2 data when used for pond detection. This shows the potential of the combination of both sensors to increase the accuracy of aquaculture pond mapping.
\end{abstract}

Key-words: Sentinel-1, Sentinel-2, Aquaculture Ponds, Texture, Supervised Classification

\section{INTRODUCTION}

Indonesia is an archipelago consisting of approximately 17,504 large and small islands, having the longest coastline in the world with a length of 104,000 km (Lasabuda, 2013). The massive coastal areas of the islands in Indonesia are suitable for the development of brackish water aquaculture. Brackish water aquaculture, as one of the supporting factors for the economy of coastal communities, has triggered the expansion of new ponds, which will continue to occur to fulfill the surrounding community's needs (Joffre et al., 2019; Ottinger et al., 2016; Porporato et al., 2020). It is necessary to monitor the sustainability of the aquaculture ponds and formulate management strategies in coastal areas to support coastal environmental conditions. For sustainable coastal area management, understanding pond distribution is the first step in determining the strategies that need to be implemented. It is essential to understand that direct data collection and monitoring of ponds individually will be a lengthy and expensive process due to the vast area of the ponds (Gusmawati et al., 2016a; Gusmawati et al., 2016b). Therefore, technology is needed to assist in pond monitoring (Duan et al., 2020; Ottinger et al., 2016).

Synthetic aperture radar (SAR) satellite observation is part of the remote sensing active system that can provide observations day and night and at various weather conditions due to its ability to

\footnotetext{
${ }^{I}$ Master Program in Remote Sensing, Department of Geographic Information Science, Faculty of Geography, Universitas Gadjah Mada, Yogyakarta, Indonesia,nurul.afdal.haris@mail.ugm.ac.id, sandiaga.kusuma@mail.ugm.ac.id,*correspondingauthor sanjiwana.arjasakusuma@ugm.ac.id, prama.wicaksono@ugm.ac.id
} 
penetrate clouds. One of the satellites that use SAR technology is Sentinel-1. The Sentinel-1 satellite provides SAR imagery free of charge and covers the whole world with a high temporal and spatial resolution (Obida et al., 2019). The Sentinel-1 mission employed C-band with dual-polarization capabilities using the combination of vertical transmittance, vertical or horizontal returns (VV and $\mathrm{VH}$, respectively), short revisit times, and fast product delivery for global observation using the constellation of two satellites (Sentinel-1A and Sentinel-1B) orbiting the poles (European Space Agency, 2013). Several studies have been conducted using solely multitemporal radar data or using radar and optical imagery in combination for aquaculture pond mapping, such as the utilization of multitemporal Sentinel-1 radar images and Landsat optical images for mapping aquaculture characteristics (Stiller et al., 2019), aquaculture pond identification based on Google Earth Engine's use of Sentinel-1 and Sentinel-2 images (Xia et al., 2020), aquaculture pond identification using the object-based image analysis (OBIA) and normalized difference water index (NDWI) methods in Taiwan, and using multitemporal Sentinel-1 radar data for pond mapping (Chen et al., 2018; Ottinger et al., 2017). Sentinel-1 data also has a significant ability to distinguish flooded land cover, such as a paddy field in the inundation phase, by utilizing cross-polarization data from Sentinel-1, although misclassification can still occur, especially regarding land cover that possesses similar characteristics with the flooded paddy field (Arjasakusuma et al., 2020). However, the textural information from Sentinel-1 has not been fully explored, especially for mapping applications.

Sentinel-1 data has been widely utilized for aquaculture pond identification, but the assessment of textural information from Sentinel-1, the gray level of co-occurrence metrics (GLCM) textures, has not been studied to identify aquaculture ponds. In this study, the mapping capability using GLCM for aquaculture pond identification as an input dataset was tested and compared with the ability of Sentinel-2 optical imagery for aquaculture pond mapping.
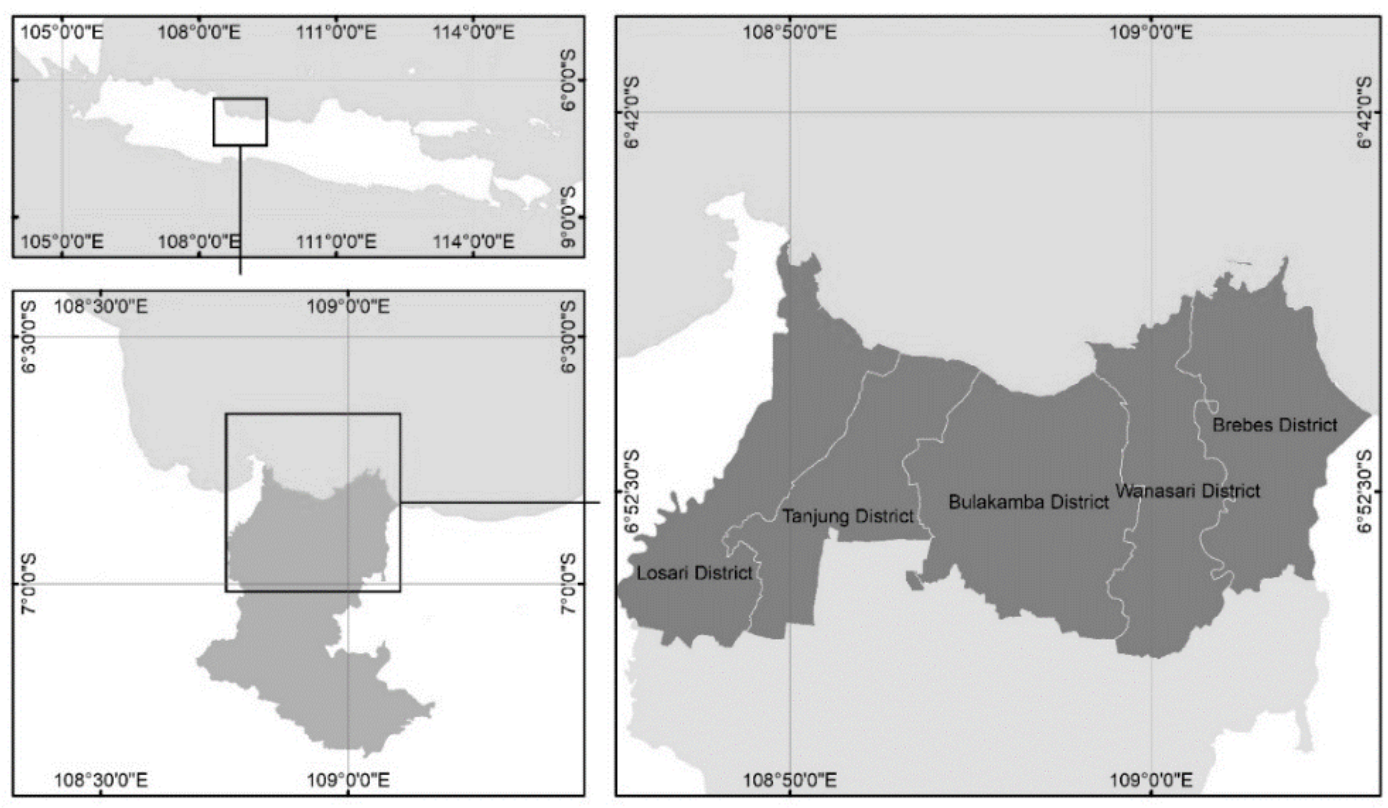

Fig. 1. Study area in the coastal area of Brebes Regency, Central Java Province.

\section{STUDY AREA}

The study area was located in Brebes Regency, Central Java Province, Indonesia. Brebes Regency is located between $6^{\circ} 44^{\prime}-7^{\circ} 21^{\prime} \mathrm{S}$ and $108^{\circ} 41^{\prime}-109^{\circ} 11^{\prime} \mathrm{E}$ (Fig. 1). The northern part of the study area is adjacent to the Java Sea, the eastern part is adjacent to the Tegal City and Tegal Regency, the southern part is adjacent to the Banyumas Regency, and the western part is adjacent to 
the West Java Province. Brebes Regency consists of 17 Districts, five of which (Losari, Tanjung, Bulakamba, Wanasari, and Brebes) are directly adjacent to the sea, and approximately $19.92 \%$ to $42.01 \%$ of the area is used for aquaculture ponds, with the Brebes district having the largest area of aquaculture ponds (Table 1).

Table 1.

Total Area of Ponds in the Coastal Area of Brebes Regency.

\begin{tabular}{cccc}
\hline District & District Area (Ha) & Ponds Area (Ha) & Percentage (\%) \\
\hline Losari & 9179 & 2602 & 28.35 \\
Tanjung & 7209 & 2555 & 35.44 \\
Bulakamba & 12036 & 2215 & 18.40 \\
Wanasari & 7534 & 1501 & 19.92 \\
Brebes & 9223 & 3875 & 42.01 \\
\hline
\end{tabular}

Source: (BPS-Statistics of Brebes Regency, 2020).

\section{DATA AND METHODS}

\subsection{Sentinel-1 Data}

This study used 12 Sentinel-1A, dual-polarization (VV and VH) images in interferometric wideswath mode (IW-SM) and ground range detected high resolution (GRDH) format with a 10-meter spatial resolution in descending orbit with a period from September 2019 to August 2020. More details regarding the Sentinel-1 images used in this analysis are presented in Appendix 1 and Appendix 2.

Preprocessing was completed using the SNAP Sentinel-1 ToolBox application by following the steps suggested by Filipponi (2019). During processing, the Sentinel-1 images were cropped to the extent of the study area. Then, the Apply Orbit File was applied by updating the metadata to acquire an accurate satellite position, followed by Thermal Noise Removal to reduce the noise effect in intersub-swath textures. Another step, namely, Calibration, was used to convert the pixel digital number value to a unitless radiometrically calibrated radar backscatter followed by Speckle Filtering to remove speckle and improve the visual quality of the SAR images. In this study, a Refined Lee Filter with a $5 \times 5$ window size was selected because it could remove noise while maintaining the quality of the pixel points and edges of the image (Rana \& Suryanarayana, 2019).

Additional steps such as Terrain Correction were applied to the data by using the digital elevation model (DEM) from the Shuttle Radar Topographic Mission (SRTM) with a 30-meter spatial resolution. Also, the orbit files were used to geometrically correct the distortion of the images caused by topography such as layover, foreshortening, and shadow. Lastly, the terrain-corrected data was converted from the previously unitless backscatter to decibel (dB) by using logarithmic transformation. In addition, to identify the variety of land cover, false-color composite or band combination using multitemporal Sentinel-1 data was completed. This step was conducted so that the existing land cover could be identified which was then used to determine the training samples for classification.

\subsection{Sentinel-2 Data}

Sentinel-2 is an optical imaging program launched as part of the European Space Agency's (ESA's) Copernicus program. Sentinel-2 data were often used to carry out terrestrial observations such as forest monitoring, land cover change detection, and natural disaster management. Sentinel-2 data are included in a multispectral, medium-resolution image with 13 spectral bands. For this study, Sentinel-2 data was acquired in July and has an $11.13 \%$ cloud cover, mostly located outside of the study area. More details on the Sentinel-2 data characteristics are presented in Appendix 3.

Atmospheric correction was applied to the data to eliminate atmospheric disturbances. This process was completed using Command Prompt by utilizing the system from Sen2Cor 2.8.0. Band 
selection was conducted to choose bands having a 10-meter spatial resolution, which were used as analysis material to match with the spatial resolution of the Sentinel-1 data. Therefore, only Band 2, Band 3, Band 4, and Band 8 were used in the image classification process. False-color composite (RGB: Band 8, Band 4, Band 3) was used to interpret the Sentinel-2 images of the training and validation areas (Fig. 2). All of the processing steps for the Sentinel-2 data were conducted using SNAP.
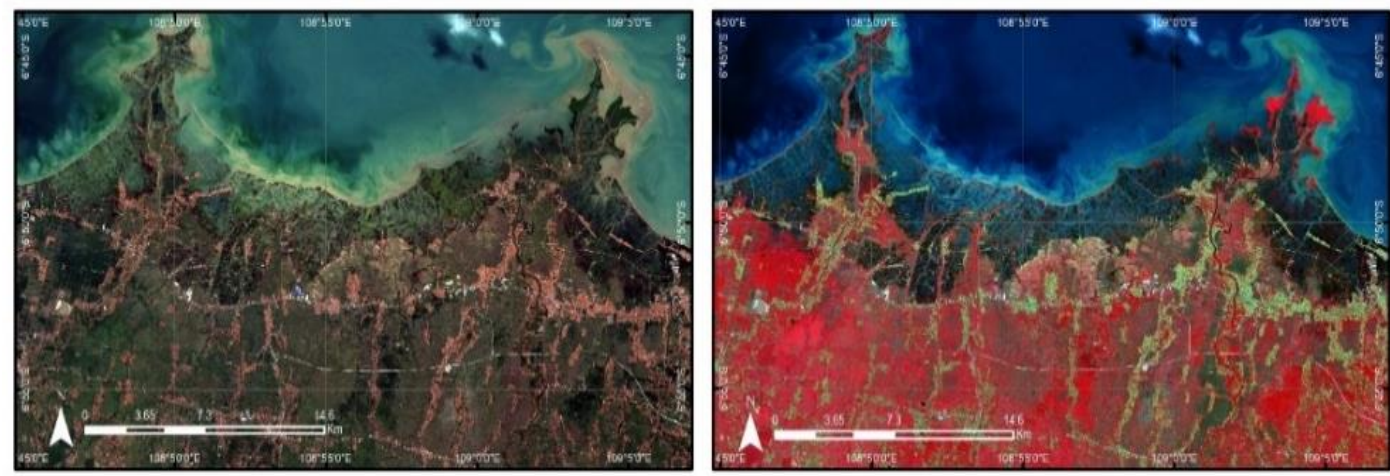

Fig. 2. Visual differences in band composite (a) True-color composite (RGB: 432);

(b) False-color composite (RGB: 843).

\subsection{Generating GLCM}

Textural analysis was performed on the Sentinel-1 data using the GLCM calculation in the SNAP software. GLCM contains integrated information concerning the direction, interval, and extent of changes of the gray level, serving as the basis for analysis of local area features in an image and their arrangement patterns (Hall-Beyer, 2017). Haralick et al. (1973) identified 14 types of texture features as part of the GLCM dataset. In this study, we used 10 types of textures (angular second moment (ASM), correlation, contrast, dissimilarity, energy, entropy, mean, variance, homogeneity, and max). These textures were used as the input dataset for the classification process. The results of the GLCM texture analysis from VH polarization can be seen in Fig. 3.

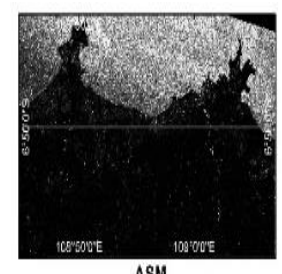

ASM

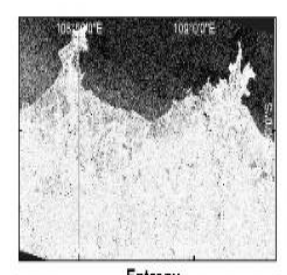

Entropy

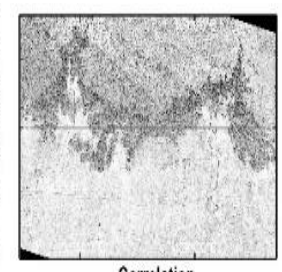

Correlation

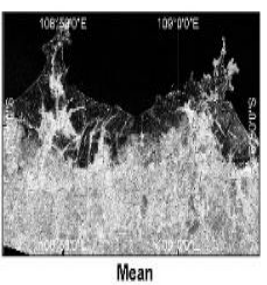

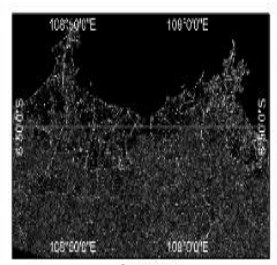

N Contrast

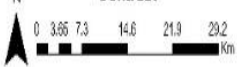

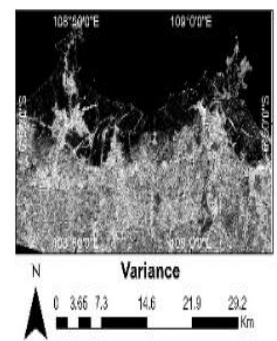

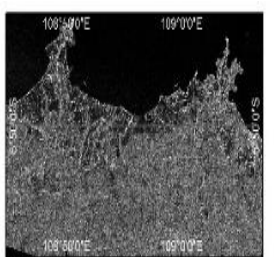

Dissimilarity

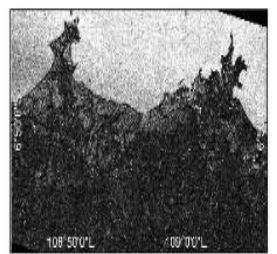

Homogeneity
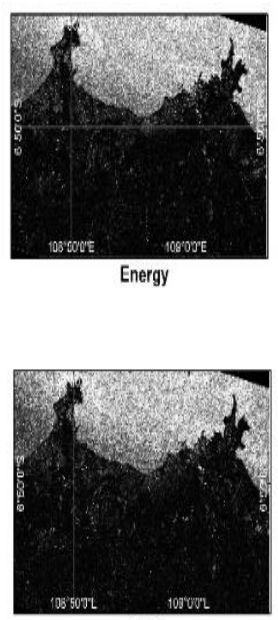

MAX

Fig. 3. GLCM texture extraction results from Sentinel-1 VH polarization. 


\subsection{Supervised Classification and Validation Analysis}

Supervised classification was used to differentiate between ponds and paddy fields using the algorithms available in the SNAP software for Sentinel-2 imagery, such as minimum distance (MD) (Rajalakshmi et al., 2013), maximum likelihood (ML) (Marini et al., 2013), K-nearest neighbor (KNN), and random forest (RF) (Kulkarni \& Lowe, 2016).

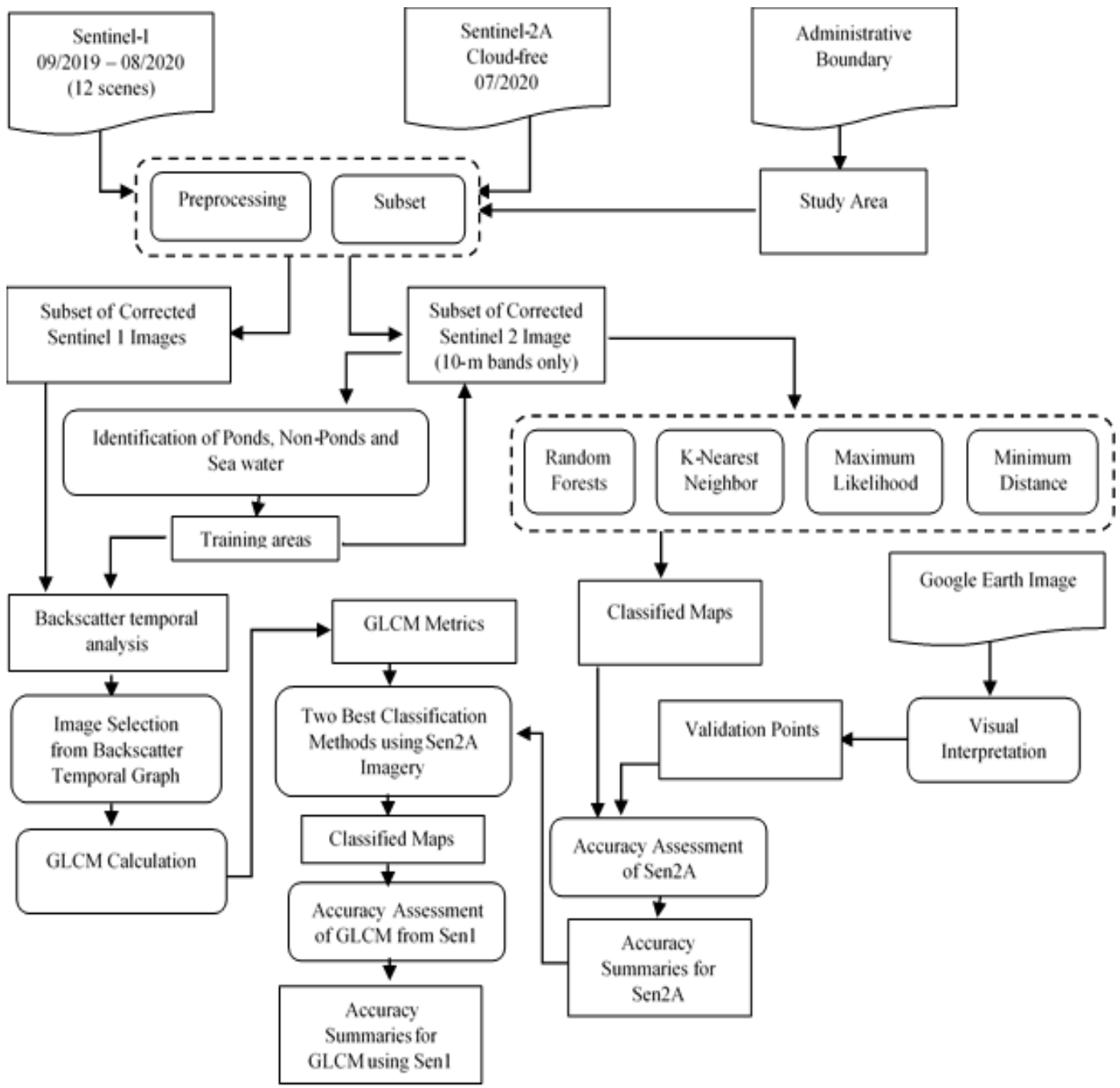

Fig. 4. Workflow of processing that was conducted in this study.

A brief explanation of each method is presented below:

1. The ML classification assumes that the statistical distribution occurs normally in each class of each band and that the calculation of the probability of a certain pixel falls into a certain class. Additionally, the pixels are assigned to a class that has a high probability (Richard, 1999).

2. The MD classification calculates the Euclidean distance from each unknown pixel to the mean vector for each class and uses the mean vector of each end member. Pixels are classified according to the nearest class based on the specified conditions except for the specified standard deviation or threshold. However, some pixels may be unclassified because they do not meet the predetermined criteria (Richards, 1999). 
3. The KNN algorithm works by classifying the number $(k)$ of neighbors that are located near to the training samples by calculating the Euclidean distance from the training data to the unclassified data (Li \& Cheng, 2009).

4. RF is a bootstrap aggregating method that creates a multiple-tree classifier by iteratively resampling the original data. The final class for the classification is determined by majority voting (Breiman, 2001).

Before classification, the training areas were collected by conducting visual interpretation using the image composite from the Sentinel-2 data. Three classes were represented in the classification process, including pond, non-pond, and seawater areas. More details about the data processing flow can be seen in Fig. 4.

The classification results obtained from Sentinel-1 and Sentinel-2 imagery were validated by using the information from the high-resolution satellite image (HRSI) available from Google Earth. Approximately 2.520 points were collected and used to test the accuracy of the classification results from the Sentinel-1 and Sentinel-2 imagery analysis. The accuracy tests were carried out using the confusion matrix and kappa coefficient methods by calculating the producer, user, and overall accuracies (PA, UA, and OA, respectively).

\section{RESULTS AND DISCUSSIONS}

\subsection{Classification Results Using Sentinel-2 Optical Bands}

The classification of Sentinel-2 images used the same classes as Sentinel-1 radar images (sea, pond, and non-pond) and used the same training data. Image classification was carried out by supervised classification with the RF, ML, MK, and KNN algorithms using the SNAP application. The purpose of using these four algorithms was to determine which algorithm was the most accurate when classifying images using the same sample data applied to Sentinel-1 image classification. The results of the Sentinel-2 image classification using the aforementioned algorithms and the comparison with the composite image using false-color can be seen in Fig. 5 below.
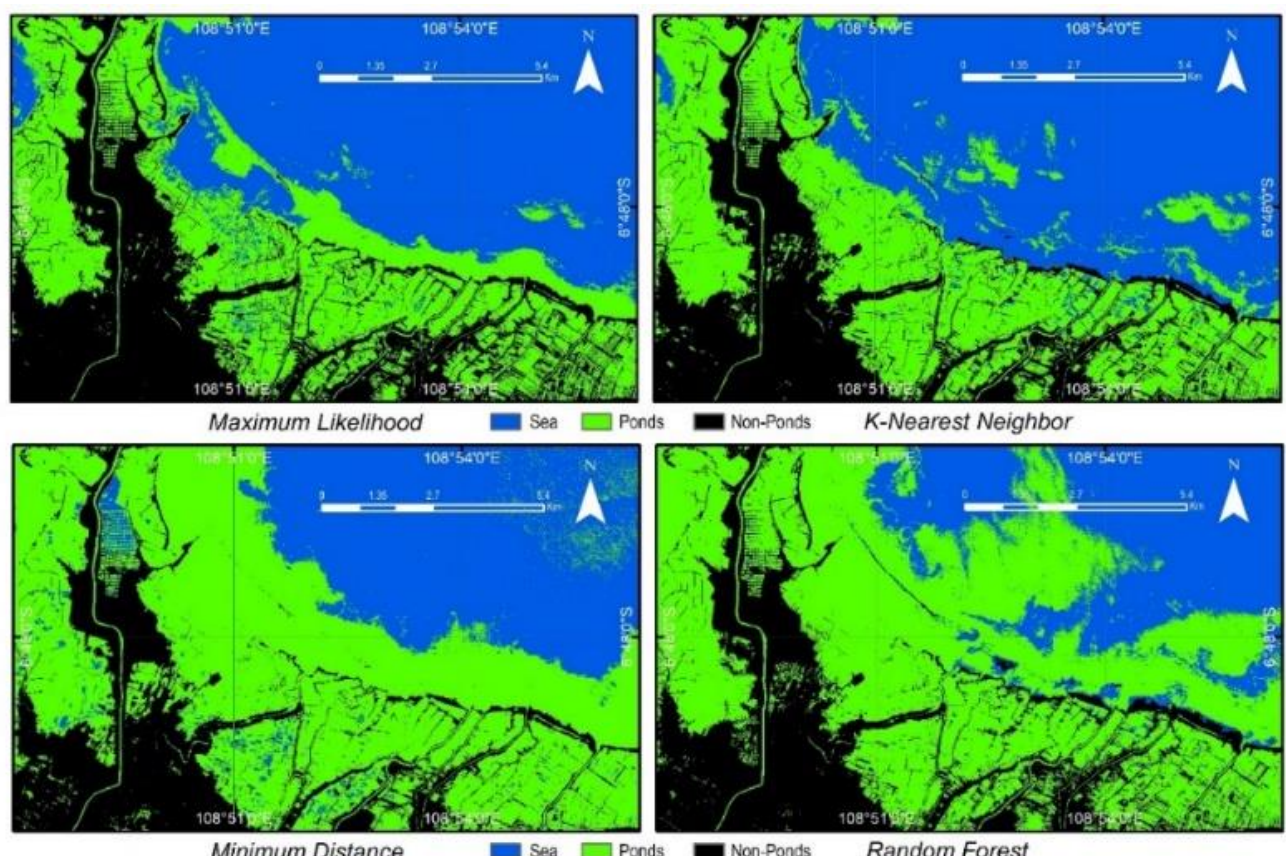

Fig. 5. Result of Sentinel-2 image classification using RF, ML, MK, and KNN algorithms. 
A narrow area is required to show more clearly the comparison of the classification results for each algorithm, as well as to identify the pond according to the given sample data based on the interpretation results. The ML and KNN classifications give good results with 0.884 and 0.876 . The accuracies of ML and KNN were better when compared to the MD and RF classifications. The results, which are a test of the accuracy of each algorithm using the confusion matrix, are presented in Table 2 below. From Table 2, it can be seen that the classification using the ML algorithm produced a better overall accuracy (88.4\%) when compared to the other classifications. The KNN algorithm follows with an overall accuracy of $87.6 \%$. The result that gives the lowest overall accuracy is the classification using the MD algorithm, having an overall accuracy of $75.4 \%$.

Accuracy Test Result of Sentinel-2 Image Classification.

Table 2.

\begin{tabular}{lccc}
\hline \multicolumn{1}{c}{ Method } & $\begin{array}{c}\text { Producer } \\
\text { Accuracy }(\boldsymbol{\%})\end{array}$ & $\begin{array}{c}\text { User } \\
\text { Accuracy } \\
(\boldsymbol{\%})\end{array}$ & $\begin{array}{c}\text { Overall Accuracy } \\
(\boldsymbol{\%})\end{array}$ \\
\hline Minimum Distance & 69.004 & 72.059 & 75.4 \\
Random Forest & 72.671 & 86.761 & 81.0 \\
Maximum Likelihood & 87.056 & 89.998 & 88.4 \\
K-Nearest Neighbor & 83.944 & 89.807 & 87.6 \\
\hline
\end{tabular}

\subsection{Selection of Sentinel-1 Data Images for Producing GLCM Features}

The GLCM textures were produced from the Sentinel-1 VH polarization data. VH polarization was used to describe surface conditions because it has a more precise visualization than VV polarization and because $\mathrm{VH}$ is more sensitive to changes in moisture on the surface cover (Arjasakusuma et al., 2020). The appearance of each image at a particular time (September 2019August 2020) can be seen in Fig. 6 below. In addition, we selected scenes with the most contrast between seawater and paddy fields to derive the GLCM metrics.

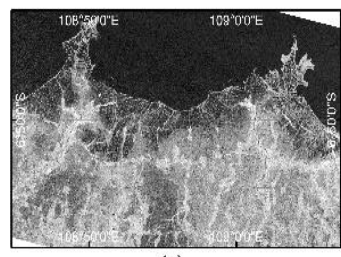

(a)

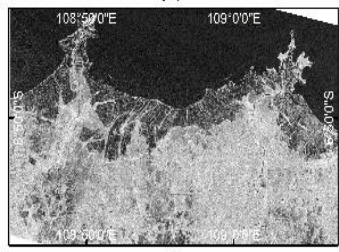

(e)

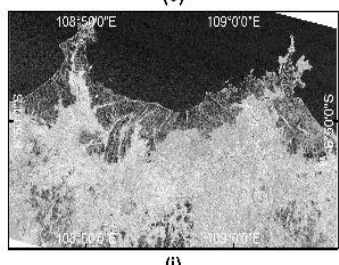

(i)

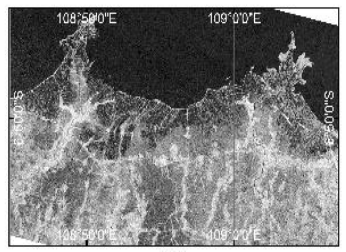

(b)

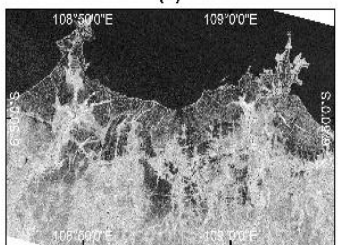

(f)

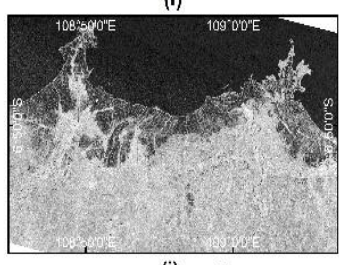

(j) $\mathrm{N}$

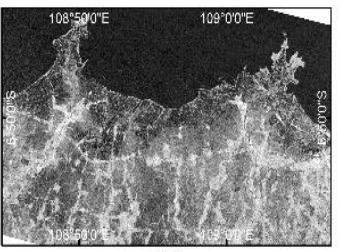

(c)

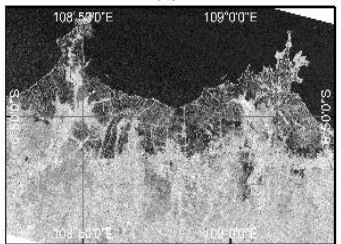

(g)

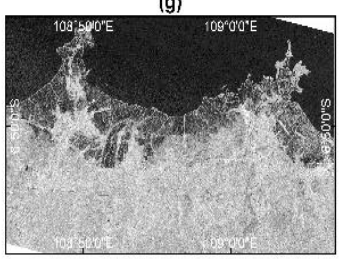

(k)

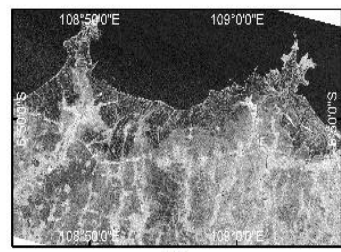

(d)

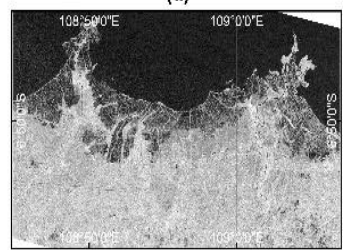

(h)

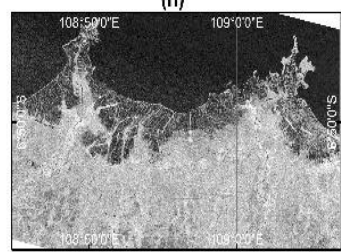

(I)

Fig. 6. Sigma_VH Polarization of Sentinel-1 (a) 07 September 2019, (b) 01 October 2019, (c) 06 November 2019, (d) 12 December 2019, (e) 05 January 2020, (f) 10 February 2020, (g) 05 March 2020, (h) 10 April 2020, (i) 04 May 2020, (j) 09 June 2020, (k) 03 July 2020, (l) 08 August 2020. 
Based on Fig. 6, which shows the Sentinel-1 image at various points in time, it can be seen that there is a different tone of the land area that is somewhat far from the coast. Based on the results of a rough interpretation, it can be assumed that these features are rice fields, which have different appearances at certain times (dark-light-dark). To prove this, further analysis was carried out by stacking or merging bands on Sentinel-1 image data at different times into one unit. After that, an RGB composite with a different time composition was formed by utilizing the same variation, which in this case was the VH polarization.

The results of this RGB composite show objects that change over time. The changes that occur can be recognized by the appearance of a variety of colors. For several objects previously interpreted, further identification and analysis of the intensity of the $\mathrm{dB}$ values were conducted, especially for sea, ponds, and paddy fields, which at one time may have similar appearances (inundation phase). The differences between the spectrum of each object sampled over 12 months can be seen in Fig. 7. From Fig. 7, we selected October 2019, June 2020, and July 2020 as the input data for calculating the GLCM textural features, due to the large differences between ponds and paddy fields during these timeframes.

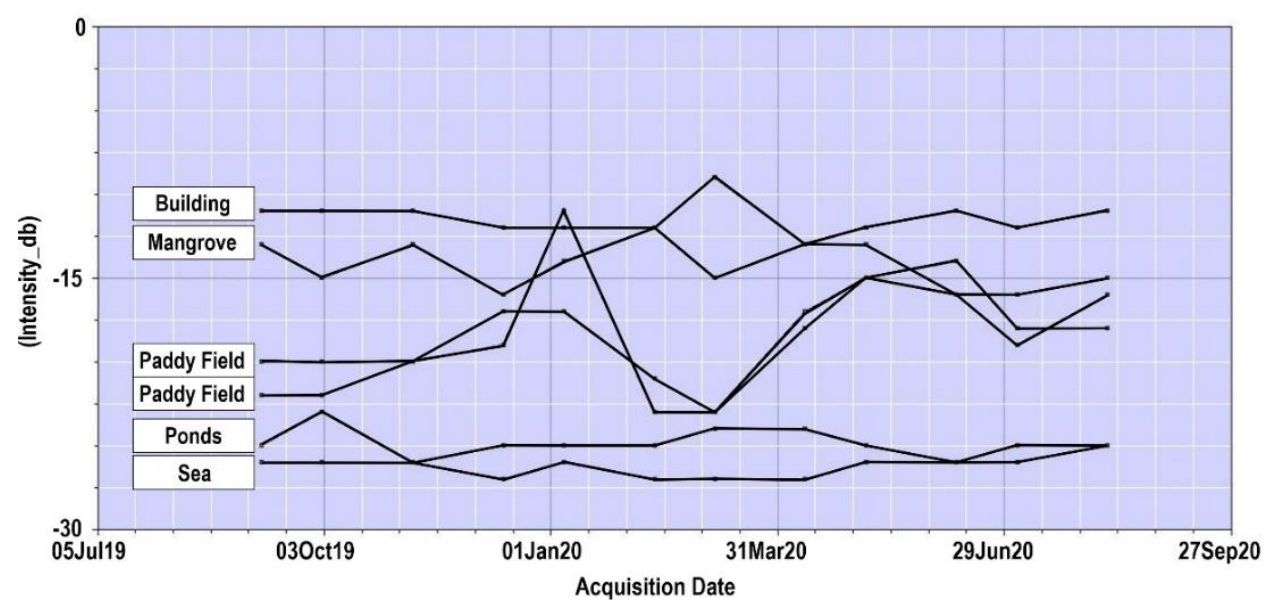

Fig. 7. The VH-backscatter spectrum of objects on Sentinel-1 images between September 2019 and August 2020.

\subsection{Supervised Classification using GLCM from Selected Sentinel-1 Data}

Supervised classification was conducted by using the generated GLCM textures from selected images on October 2019, June 2020, and July 2020. There were 10 GLCM textures for each image, which brings the total number of input variables for classification to 30 textures for one polarization. We conducted the comparison of supervised classification with the ML and KNN algorithms using GLCM textures from VH polarization. The ML and KNN algorithms were employed since they performed well during the Sentinel-2 classification. However, we also conducted the supervised ML and KNN classification using VV polarization for comparison purposes. The classification results from both polarizations can be seen in Fig. 8.

The accuracy assessment conducted on the results in Fig. 8, using the input GLCM textures from multitemporal $\mathrm{VH}$ polarization, identified the ML algorithm as the most accurate, having an OA of $92.16 \%$. For the aquaculture ponds class, the PA was $89.30 \%$ with a UA of $94.23 \%$. The worst classification result was produced by using textures from VV, which showed a misclassification between seawater and pond. The accuracy using VV polarization lies between $88.11 \%(\mathrm{KNN})$ and $89.2 \%$ (ML). Complete results of the PA, UA, and OA for the aquaculture class can be found in Table 3. 

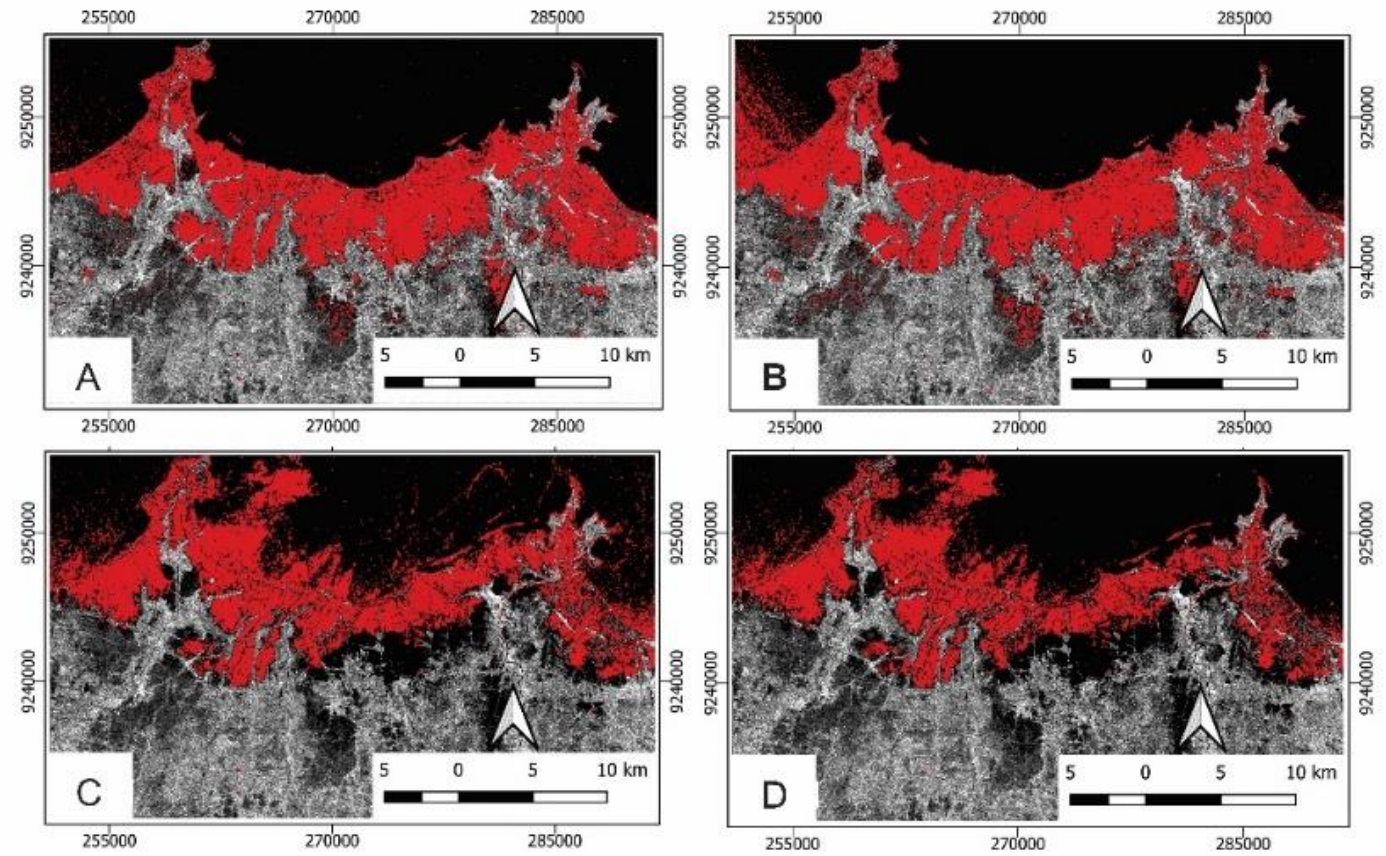

Fig. 8. Results of classification with textures from VH using (a) ML and (b) KNN, and from VV using (c) ML and (d) KNN.

Table 3.

Accuracy Assessment using GLCM from Sentinel-1 as the Input for Image Classification.

\begin{tabular}{l|lccc}
\hline Polarization & \multicolumn{1}{|c}{ Method } & $\begin{array}{c}\text { Producer } \\
\text { Accuracy } \\
(\boldsymbol{\%})\end{array}$ & $\begin{array}{c}\text { User } \\
\text { Accuracy } \\
(\boldsymbol{\%})\end{array}$ & $\begin{array}{c}\text { Overall } \\
\text { Accuracy }(\%)\end{array}$ \\
\hline \multirow{3}{*}{ VV } & Maximum Likelihood & 87.86 & 89.66 & 89.20 \\
& K-nearest neighbor & 81.91 & 92.72 & 88.11 \\
VH & Maximum Likelihood & 89.30 & 94.23 & 92.15 \\
\hline
\end{tabular}

\section{CONCLUSIONS}

This study has analyzed the potential of textural information using GLCM from multitemporal Sentinel-1 data for classifying aquaculture ponds when compared with the 10-meter bands of optical Sentinel-2 data. Sentinel-1's GCLM textures using VH polarization were better than Sentinel-2's for distinguishing aquaculture ponds, with a 92\% OA, 89.30\% PA, and 94.23\% UA using the ML algorithm. Meanwhile, the highest OA produced by the Sentinel-2 data was $88.4 \%$ using the ML algorithm. Misclassification of ponds was frequently generated due to the similarities between ponds and seawater during coastal flooding that often occurred in the study area. In the future, the combination of all GLCM features or the combination from radar backscatter and texture with optical image classification can be tested with various methods to produce the highest accuracy.

Acknowledgments: The authors thank ESA for providing free access to Sentinel-1 radar data and Sentinel-2 optical data. There is no external funding associated with this study.

Author Contribution: S.A. and P.W. assist in designing research concepts. S.A, S.S.K, N.A.H. prepare up to data processing. S.K. and P.W. provide input in research results. 


\section{R E F E R E N C E S}

European Space Agency. (2013). Sentinel-1: Instrument Payload. https://sentinel.esa.int/

Arjasakusuma, S., Swahyu Kusuma, S., Rafif, R., Saringatin, S., \& Wicaksono, P. (2020). Combination of Landsat 8 OLI and Sentinel-1 SAR Time-Series Data for Mapping Paddy Fields in Parts of West and Central Java Provinces, Indonesia. ISPRS International Journal of Geo-Information, 9(11), 663. https://doi.org/10.3390/ijgi9110663

BPS-Statistics of Brebes Regency. (2020). Kabupaten Brebes dalam Angka (Brebes Regency in Figures) (B.-S. of B. Regency (ed.)). BPS-Statistics of Brebes Regency. https://brebeskab.bps.go.id/publication/2020/04/27/d3f4377eb63e5edd93cb6217/kabupaten-brebes-dalamangka-2020.html

Breiman, L. (2001). Random forests. Random Forests, 45, 5-32. https://doi.org/10.1023/A:1010933404324

Chen, W., Lin, Y., \& Tseng, K. (2018). Monitoring Temporal Variation of Ecological Ponds in Taiwan by Using Sentinel Images. 20, 11976. https://ui.adsabs.harvard.edu/\#abs/2018EGUGA..2011976C/abstract

Duan, Y., Li, X., Zhang, L., Chen, D., Liu, S., \& Ji, H. (2020). Mapping national-scale aquaculture ponds based on the Google Earth Engine in the Chinese coastal zone. Aquaculture, 520(November 2019), 734666. https://doi.org/10.1016/j.aquaculture.2019.734666

Gusmawati, Niken F., Zhi, C., Soulard, B., Lemonnier, H., \& Selmaoui-Folcher, N. (2016). Aquaculture pond precise mapping in Perancak Estuary, Bali, Indonesia. Journal of Coastal Research, 1(75), 637-641. https://doi.org/10.2112/SI75-128.1

Gusmawati, Niken Financia, Andayani, A., \& Mu' awanah, U. (2016). Pemanfaatan Data Penginderaan Jauh Resolusi Tinggi Untuk Pemetaan Tambak Di Kecamatan Ujung Pangkah, Gresik. Jurnal Kelautan Nasional, 11(1), 35. https://doi.org/10.15578/jkn.v11i1.6065

Hall-Beyer, M. (2017). GLCM Texture: A Tutorial v. 3.0. Arts Research \& Publications, 2017-03, 75. https://prism.ucalgary.ca/handle/1880/51900\%0Ahttp://hdl.handle.net/1880/51900

Haralick, R. M., Shanmugam, K., \& Dinstein, I. (1973). Textural Features for Image Classification. SEG Technical Program Expanded Abstracts, 3(6), 610-621. https://doi.org/10.1190/segam2015-5927230.1

Joffre, O. M., Poortvliet, P. M., \& Klerkx, L. (2019). To cluster or not to cluster farmers? Influences on network interactions, risk perceptions, and adoption of aquaculture practices. Agricultural Systems, 173(February), 151-160. https://doi.org/10.1016/j.agsy.2019.02.011

Lasabuda, R. (2013). Regional Development in Coastal and Ocean in Archipelago Perspective of The Republic of Indonesia. Jurnal Ilmiah Platax, I, 92-101. https://doi.org/10.35800/jip.1.2.2013.1251

Li, Y., \& Cheng, B. (2009). Oh 2. 2009 17th International Conference on Geoinformatics, Geoinformatics 2009, 1-4. https://doi.org/10.1109/GEOINFORMATICS.2009.5293389

Obida, C. B., Blackburn, G. A., Whyatt, J. D., \& Semple, K. T. (2019). River network delineation from Sentinel1 SAR data. International Journal of Applied Earth Observation and Geoinformation, 83(July), 101910. https://doi.org/10.1016/j.jag.2019.101910

Ottinger, M., Clauss, K., \& Kuenzer, C. (2016). Aquaculture: Relevance, distribution, impacts and spatial assessments - A review. Ocean and Coastal Management, 119(2016), 244-266. https://doi.org/10.1016/j.ocecoaman.2015.10.015

Ottinger, M., Clauss, K., \& Kuenzer, C. (2017). Large-scale assessment of coastal aquaculture ponds with Sentinel-1 time series data. Remote Sensing, 9(5). https://doi.org/10.3390/rs9050440

Porporato, E. M. D., Pastres, R., \& Brigolin, D. (2020). Site Suitability for Finfish Marine Aquaculture in the Central Mediterranean Sea. Frontiers in Marine Science, 6(January), 1-12. https://doi.org/10.3389/fmars.2019.00772

Rana, V. K., \& Suryanarayana, T. M. V. (2019). Evaluation of SAR speckle filter technique for inundation mapping. Remote Sensing Applications: Society and Environment, 16(October), 100271. https://doi.org/10.1016/j.rsase.2019.100271

Stiller, D., Ottinger, M., \& Leinenkugel, P. (2019). Spatio-temporal patterns of coastal aquaculture derived from Sentinel-1 time series data and the full Landsat archive. Remote Sensing, 11(14), 1-18. https://doi.org/10.3390/rs11141707

Xia, Z., Guo, X., \& Chen, R. (2020). Automatic extraction of aquaculture ponds based on Google Earth Engine. Ocean and Coastal Management, 105348. https://doi.org/10.1016/j.ocecoaman.2020.105348 